\title{
Dev konka bülloza piyoseli
}

\section{Giant concha bullosa pyocele}

\section{Cüneyt Kucur, Onur Erdoğan*, Sermin Tok, Bekir Şanal, Mustafa Özkan, Nadir Yildırım}

Kulak Burun Boğaz Anabilim Dalı (Yrd. Doç. Dr. C. Kucur, Dr. O. Erdoğan, Doç Dr. N. Yıldırım), Radyoloji Anabilim Dalı (Yrd. Doç. Dr. B. Şanal), Dumlupınar Üniversitesi Tıp Fakültesi, TR-43100 Kütahya, Radyoloji Bölümü (Dr. S. Tok), Kulak Burun Boğaz Anabilim Dalı (Dr. M. Özkan), Evliya Çelebi Eğitim ve Araştırma Hastanesi, TR-43100 Kütahya

\section{Özet}

Konka bülloza,havalanmış (pnömatize) veya içinde bir havalı hücre bulunan orta konka için kullanılan bir terimdir. Genellikle asemptomatik olmakla birlikte pnömatizasyonun büyüklüğüne ve nazal septumla olan ilişkisine göre burun tıkanıklığı semptomları verebilir ve ostiomeatal komplekse bası oluşturmakta ise tikanmasina neden olarak sinüzite yol açabilir. Piyosele dönüşmesi nadirdir. Dev konka bülloza endoskopík muayenede orta konkanin genişlemiş bir bölümü olarak görülür. Konka bülloza kesin tanısı paranazal sinus bilgisayarlı tomografisi (BT) ile koyulur. Tedavisinde endoskopik olarak orta konkanın lateral parsiyel rezeksiyonu yeterli ve minimal invazif bir yöntemdir. Bu yazıda sağ nazal pasajı tamamen tıkayan ve nazal vestibüle kadar uzanım gösteren ve aynı tarafta sinüzite yol açan tek taraflı dev konka bülloza piyoseli olgusu sunulmuştur.

Anahtar sözcükler: Orta konka, konka bülloza, piyosel

\begin{abstract}
"Concha bullosa" is the term used for pneumatized or air cell-containing middle turbinate. It is usually asymptomatic. However, depending on its size, contact with the nasal septum and infringement to the ostio-meatal complex, it may cause nasal obstruction and sinusitis. Rarely, it turns into a "pyocele". Giant or extensive concha bullosa is seen as an enlarged portion of middle turbinate. It is diagnosed through paranasal computarized tomography. Endoscopic partial medial resection of the enlarged turbinate is sufficient for its surgical treatment. We herewith present a case with extensive concha bullosa, which transformed into a pyocele and extended to the nasal vestibule. It had caused total nasal obstruction and complicated with the sinusitis on the same side.
\end{abstract}

Keywords: Middle turbinate, concha bullosa, pyocele

Geliş tarihi/Received: 09 Ağustos 2013; Kabul tarihi/Accepted: 20 Mayıs 2014

\section{*iletişim adresi:}

Dr. Onur Erdoğan, Kulak Burun Boğaz Anabilim Dalı, Dumlupınar Üniversitesi Tıp Fakültesi, TR-43100 Kütahya. E-posta: onurerdogan38@ gmail.com

\section{Giriş}

Paranazal bölgeyi oluşturan anatomik yapıların çok sayıda konjenital anomalileri ve anatomik varyasyonları tespit edilmiştir. Bunlar içerisinde konka bülloza, septum pnömatizasyonu, paradoks orta konka, Haller hücresi, Onodi hücresi, anterior klinoid proçes pnömatizasyonu, unsinat proçes pnömatizasyonu sayılabilir [1]. Bu varyasyonlar içerisinde en sık görüleni orta konkanın değişik derecelerdeki pnömatizasyonu olarak tanımlanan konka bülloza, nazal pasaj içerisinde lateral nazal duvarın önemli ve sık rastlana bir anatomik varyasyonudur [2]. Konka pnömatizasyonu genellikle orta konkada görülmekle birlikte daha az oranda üst ve alt konkalarda da rastlanabilmektedir. Konka 
bülloza görülme sıklığı araştırmalarda geniş bir aralıkta (\%13,2-72,2) bulunmuştur [1-3]. Olguların yaklasık \%55 kadarında anterior etmoid hücreler, \%45'lik bölümünde ise posterior etmoid hücreler orta konkanın pnömatizasyonu ile ilişkilendirilmektedir [4]. Konka bülloza asemptomatik olabileceği gibi burun tıkanıklı̆̆ı, postnazal akıntı, baş ağrıs1 ve hiposmi gibi semptomlara sebep olabilir [5]. Enfekte olduklarında ise pyosele dönüşerek orbital ve intrakraniyal komplikasyonlara sebep olabilirler [6]. Konka bülloza piyoseline çok nadir rastlanır [7]. Bildirilmiş konka piyoseli olgularının az da olsa birbirinden farklı morfolojik ve klinik özellikler sergilemesi ve bazılarının komplikasyonlara neden olması nedeni ile bu tür ender patolojilerin yayınlanmasının konuyla ilgili literatüre katkı sağlayacağı düşüncesi ile burun tıkanıklığı ve intermittan olan baş ağrısıyla başvuran nazal vestibüle kadar uzanan tek taraflı dev konka bulloza piyoseli bulunan bir olgu sunulmaktadır.

\section{Olgu sunumu}

Elli sekiz yaşında kadın hasta, yaklaşık beş yıldır devam eden, özellikle burnun sağ tarafında mevcut olan burun tıkanıklığı ve intermittan maksillo-fasiyal tipte baş ağrısı şikayetiyle kulak burun boğaz kliniğine başvurdu. Hastanın anterior rinoskopik muayenesinde să̆ nazal pasajı tamamen dolduran, düzgün yüzeyli bir kitle mevcuttu (Resim 1). Nazal septum sola deviye ve sol alt konka hipertrofik idi. Hastanın hematolojik ve kan biyokimya parametreleri normal sınırlardaydı. Paranazal sinüs tomografisinde sağ nazal kaviteyi dolduran ileri derecede pnömatize ve hava-sıvı seviyesi gösteren dev sağ orta konka ile birlikte nazal septumun 2'nci alanda sola deviye olduğu görüldü. Büllöz konkanın en büyük anteroposterior çapı $4 \mathrm{~cm}$, en büyük süperior inferior çapı $4,5 \mathrm{~cm}$, en büyük mediolateral çap $1,5 \mathrm{~cm}$ idi (Resim 2).

Operasyon kararı verildikten sonra hastaya muhtemel riskler sözel olarak anlatılarak, aydınlatılmış yazılı onam alındı. Genel anestezi altında yapılan ameliyata başlanmadan önce büllöz konkaya yapılan ponksiyonda pürülan materyal geldiği görüldü. Sonrasında endoskopik olarak orta konka inferomedialinden rezeksiyon yapılarak ostiomeatal kompleks açıklığını sağlayacak şekilde parsiyel orta konka rezeksiyonu, maksiler sinüs ostiumu genişletilmesi, etmoid hücrelerin temizlenmesi ve karşı taraf alt konkaya radyofrekans uygulaması ile sol nazal pasajda darlık yapan septal kıkırdak eksizyonu işlemleri gerçekleştirildi. Operasyon sırasında ve sonrasında herhangi bir komplikasyon gelişmedi. Postoperatif 3'üncü ayda yapılan kontrolde hastanın nazal solunumla ilgili bir şikayeti yoktu ve yapılan endoskopik muayenesinde nazal pasajın açık olduğu izlendi (Resim 3).

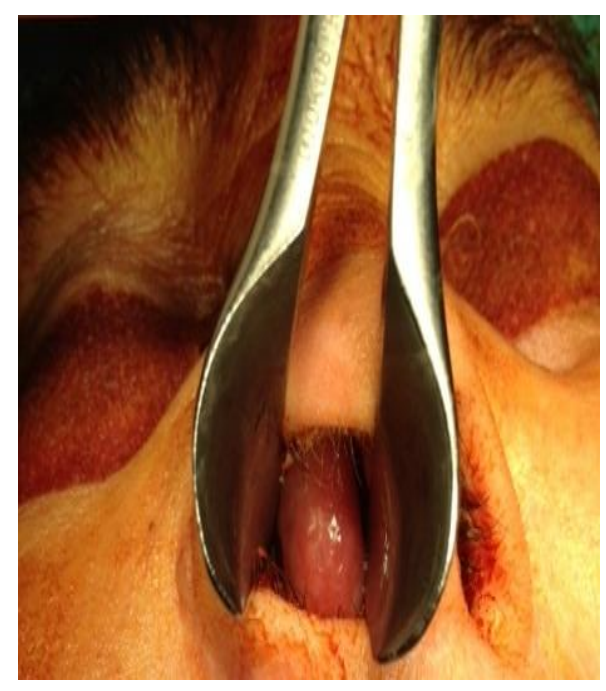

Resim 1. Anterior rinoskopik muayene. 


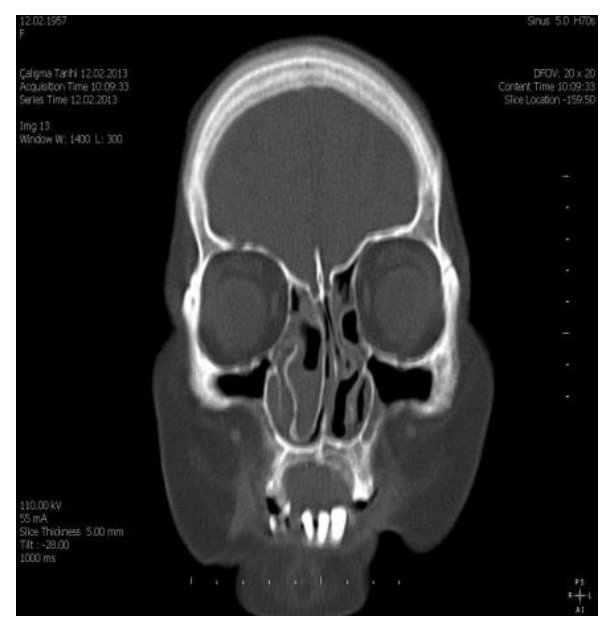

Resim 2. Preoperatif paranazal bilgisayarlı tomografi görüntüsü.

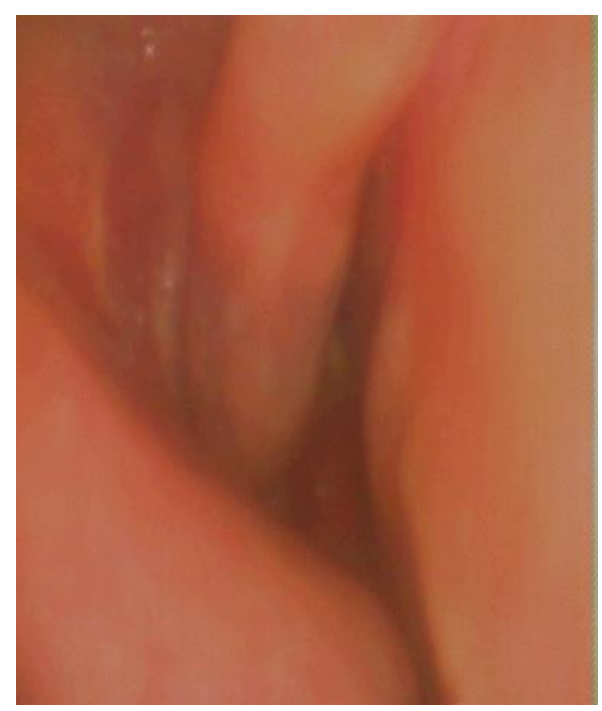

Resim 3. Postoperatif endoskopik muayene görüntüsü.

\section{Tartışma}

Konka büllozanın oluşum mekanizması tam olarak aydınlatılamamış olup bu konuda farklı teoriler ortaya atılmıstır. Bunların en çok bilinenlerinden biri olan "e vacua" teorisine göre septum deviasyonu oluştuktan sonra deviasyonun karşı tarafinda oluşan boşluk ve nazal kavitenin türbülan hava akım paterni konka bülloza oluşumuna zemin hazırlamaktadır [8]. Uzun ve ark. [9]'ları bu teoriyi destekler nitelikteki çalışmalarında, 140 vakadan oluşan bir serinin tomografilerini incelemişler ve ileri derecede septum deviasyonu olan olgularda konka bülloza görülme sıklığının arttığını bildirmişlerdir. Buna karsın konka bülloza sıklığının septum deviasyonun derecesiyle değişmeyip, orta konkadaki pnömatizasyon miktarının arttığını savunan çalışmalar da mevcuttur [2]. Konka büllozanın unilateral ve bilateral olarak görülme sıklıkları birbirine yakındır. Bilateral konka bülloza oranı \%45-\%61,5 olarak bildirilmiştir [10]. Bilateral görülüyor olması konka bülloza oluşumunun septum deviasyonundan bağımsız olduğu tezini destekler nitelikte gözükmektedir. Fakat bizim hastamızda sağda tek taraflı olarak dev bir 
konka bülloza mevcut olmasına karşın septum sola doğru deviye idi.

Konka bülloza çoğunlukla asemptomatiktir ve sıklıkla tesadüfen saptanır; 172 koronal sinus BT incelemesinde, konka bülloza, sinus hastalığı olan hastaların \%28'inde ve sinüs hastalığg olmayanların ise \%26'sında bulunmuştur [11]. Boyutlarına bağlı olarak burun tıkanıklığ çıkabilir [12, 13]. Kitle etkisiyle ostiomeatal kompleksin havalanmasını ve sekresyonların drenajını bozması halinde sinüs patolojilerine sebep olabilir [15]. Bizim hastamızın yakınması burun tıkanıklı̆̆ı ve aralıklı baş ağrısıydı. Çekilen paranazal sinüs tomografisinde burun boşluğunda ileri derecede yer kaplayan pnömatize dev orta konkanın maksiler sinüs, frontal sinüs, sfenoid sinüs ve ön etmoid sinüslerin havalanmasını bozduğu ve özellikle etmoid hücrelerde enflamasyona neden olduğu görülmekte idi.

Tanıda anterior rinoskopik ve endoskopik incelemeleri takiben ilk aşama radyolojik incelemedir. Seçkin görüntüleme yöntemi olan BT'de kitlenin özellikleri ve sınırları hakkında fikir edinilebilmektedir [11]. İntranazal kitlelerde cerrahi tedavi öncesi ayrıc1 tanı yapılmalıdır. Kesin tanı biyopsi ve spesimenin patolojik incelenmesiyle konulabilmektedir. Ancak jüvenil anjiyofibrom ve hemanjiyom gibi vasküler lezyonlar ve intrakranial yapılarla ilişkili lezyonlarda biyopsi yüksek risk taşımaktadır. Beyin omurilik sıvısı kaçağı veya masif kanama gibi komplikasyonlardan sakınmak için, biyopsi öncesi seçilmiş görüntüleme metodlarıyla (yüksek rezolüsyonlu BT,BT sisternografi,MRI sisternografi,radyonüklid sisternografi,intratekal fluorescin) tanı desteklenmelidir [3, 4]. Bizim olgumuzun tomografik inceleme bulguları dev konka bülloza ile uyumlu idi.ayrıca kitlenin içinde hava sıvı seviyesi izlenmesi öncelikli olarak konka piyosel düşündürmekteydi. Ameliyatın başlangıcında yapılan aspirasyonda pürülan mai gelmesi de konka bülloza piyoseli tanısını desteklemiştir

Konka büllozanın konkada tuttuğu yere göre 3 farklı tipi tanımlanmıştır. Orta konkanın vertikal lamelinde pnömatizasyon varsa lamellar, inferior segmentinde pnömatizasyon varsa büllöz, tüm orta konka pnömatize ise ekstensif form olarak tanımlamaktadırlar. Patolojik formlar ise genelikle bülböz ve ekstensif formlarda görülmektedir [4, 11, 12]. Bizim olgumuzda da ekstinsif tipteki büllöz konkanın piyosele dönüşmüş olması bu bilgiyi desteklemektedir.

Literatürde konka bülloza piyoseline bağlı subdural ampiyem ve orbital komplikasyonlar bildirilmiştir [6]. Bu nedenle mutlaka cerrahi olarak tedavi edilmelidir. Cerrahi tedavisi konka bülloza cerrahisine benzer şekilde endoskopik yolla patolojik konkanın rezeksiyonudur. Bazı yazarlar piyosel oluşan dev konkayı subtotal rezeke ettiklerini bildirmişlerdir [15]. Ancak olguların büyük çoğunluğu bizim de yaptığımız gibi patolojik konkayı parsiyel olarak rezeke etmişler ve bu işlem tedavi için yeterli olmuştur $[8,12$, 13]. Gerektiğinde aynı seansta bizim olgumuzda da uyguladığımız üzere hastalıklı sinüslere de müdahale edilebilir. Olgumuz, aynı zamanda konka büllozanın, özellikle büyük ve enfekte olduğunda sinüzite neden olabildiğini de teyit etmektedir.

Orta konkanın olgumuzda olduğu gibi büyük (ekstensif) pnömatizasyonu ve bunun piyosele dönüşmesi ender görülür ve bu durumun kesin nedeni belli değildir. Bu olguda "e vacua" teorisi muhtemel patogenezi açıklamaktadır. Bununla birlikte pnömatizayonun büyüklüğü ile piyosel oluşumu arasında muhtemel bir ilişki mevcuttur. Ayrıca büyük ve enfekte konka büllozanın sinüzite eşlik etmesi muhtemeldir.

Sonuç olarak; dev boyutlarda ve piyosele dönüşmüş konka bülloza olgularında dahi minimal invaziv endoskopik yöntem tedavi için yeterli olabilmektedir. 


\section{Kaynaklar}

1. Bolger WE, Butzin CA, Parsons DS. Paranasal sinus bony anatomic variations and mucosal abnormalites: CT analysis for endoscopic sinus surgery. Laryncoscope 1991; 101: 56-64.

2. Uygur K, Tüz M, Doğru H. The correlation between septal deviation and concha bullosa. Otolaryngol Head Neck Surg 2003; 129: 33-6.

3. Hatipoğlu HG, Cetin MA, Yüksel E. Concha bullosa types: Their relationship with sinusitis, ostiomeatal and frontal recess disease. Diagn Interv Radiol 2005; 11: 145-9.

4. Kantarci M, Karasen RM, Alper F, Onbas O, Okur A, Karaman A. Remarkable anatomic variations in paranasal sinus region and their clinical importance. Eur J Radiol 2004; 50: 296-302.

5. Caughey RJ, Jameson MJ, Gross CW, Han JK. Anatomic risk factors for sinus disease: Fact or fiction? Am J Rhinol 2005; 19: 334-9.

6. Bahadir O, Imamoglu M, Bektas D. Massive concha bullosa pyocele with obital extention. Auris Nasus Larynx 2006; 33: 195-8.

7. Eyibilen A. A case of concha bullosa pyocele leading to complete occlusion of the nasal passage. Kulak Burun Bogaz Ihtis Derg 2001; 8: 332-4.

8. Stammberger H. Fonctional endoscopic sinus surgery, the Messerklinger technique. Philadelphia: B. C Decker; 1991: 156-68.

9. Uzun L, Savranlar A. Orta konka pnömatizasyonu; 140 vakalık serinin bilgisayarlı tomografi ile incelenmesi. Kulak Burun Bogaz ve Bas Boyun Cerrahisi Dergisi 2004; 12: 54-8.

10. Unlü HH, Akyar S, Caylan R, Nalça Y. Concha bullosa. J Otolaryngol 1994; 23: 23-7.

11. Kayalioglu G, Oyar O, Govsa F: Nasal cavity and paranasal sinus bony variations: A computed tomographic study, Rhinology 2000; 38: 108-13.

12. Abdel-Aziz M. Mucopyocele of concha bullosa presenting as a large nasal mass. J Craniofac surg 2011; 22: 1141-2

13. Okuyucu S, Akoğlu E, Dağlı AS. Concha bullosa pyecele. Eur Arch Otorhinolaryngol 2008; 265: 373-5.

14. Yuca K, Kiris M, Kiroglu AF, Bayram I, Cankaya H. A case of concha pyocele (concha bullosa mucocele) mimicking intranasal mass. B-ENT 2008; 4: 25-7.

15. Keleş B, Celik H, Aydin E. A case of concha bullosa pyocele Kulak Burun Bogaz Ihtis Derg 2007; 17: 239-41. 